\title{
Cloning and functional characterization of three terpene synthases from lavender (Lavandula angustifolia)
}

\author{
Christian Landmann ${ }^{\mathrm{a}}$, Barbara Fink ${ }^{\mathrm{a}}$, Maria Festner ${ }^{\mathrm{a}}$, Márta Dregus ${ }^{\mathrm{b}}$, \\ Karl-Heinz Engel ${ }^{\mathrm{b}}$, Wilfried Schwab ${ }^{\mathrm{a}, *}$ \\ ${ }^{a}$ Biomolecular Food Technology, Technical University Munich, Lise-Meitner-Str. 34, 85354 Freising, Germany \\ ${ }^{\mathrm{b}}$ Chair of Food Technology, Technical University Munich, Am Forum 2, 85350 Freising, Germany
}

Received 2 May 2007, and in revised form 18 June 2007

\begin{abstract}
The essential oil of lavender (Lavandula angustifolia) is mainly composed of mono- and sesquiterpenes. Using a homology-based PCR strategy, two monoterpene synthases (LaLIMS and LaLINS) and one sesquiterpene synthase (LaBERS) were cloned from lavender leaves and flowers. LaLIMS catalyzed the formation of $(R)-(+)$-limonene, terpinolene, $(1 R, 5 S)-(+)$-camphene, $(1 R, 5 R)-(+)-\alpha$-pinene, $\beta$-myrcene and traces of $\alpha$-phellandrene. The proportions of these products changed significantly when $\mathrm{Mn}^{2+}$ was supplied as the cofactor instead of $\mathrm{Mg}^{2+}$. The second enzyme LaLINS produced exclusively $(R)-(-)$-linalool, the main component of lavender essential oil. LaBERS transformed farnesyl diphosphate and represents the first reported trans- $\alpha$-bergamotene synthase. It accepted geranyl diphosphate with higher affinity than farnesyl diphosphate and also produced monoterpenes, albeit at low rates. LaBERS is probably derived from a parental monoterpene synthase by the loss of the plastidial signal peptide and by broadening its substrate acceptance spectrum. The identification and description of the first terpene synthases from L. angustifolia forms the basis for the biotechnological modification of essential oil composition in lavender.
\end{abstract}

(c) 2007 Published by Elsevier Inc.

Keywords: $(R)$-Linalool synthase; $(R)$-Limonene synthase; Bergamotene synthase; Lavender; Lavandula angustifolia; Monoterpene; Sesquiterpene

Many members of the botanical family Lamiaceae produce considerable amounts of essential oils. Within this family the genus Lavandula comprises 30 known species among which three are economically important: Lavandula angustifolia, Lavandula latifolia and the hybrid lavandin $L$. angustifolia $\times L$. latifolia $[1,2]$. The essential oil of the highest quality is distilled from the flowering tips of L. angustifolia, the 'true lavender', and its characteristic scent has been prized since ancient times [3]. It is used in soaps, washing agents and per-

\footnotetext{
The nucleotide sequences reported in this article have been deposited in the GenBank database under Accession Nos. DQ263740 (LaLIMS), DQ263741 (LaLINS) and DQ263742 (LaBERS).

* Corresponding author. Fax: +49 (0) 8161548595.
}

fumes, but is also added as a flavor to food and beverages [4]. Additionally lavender is regarded as a pharmaceutical plant with predominantly sedative effects employed in aromatherapy [5].

Species of the Lamiaceae family synthesize and accumulate their essential oils in the secretory oil glands, which are specialized structures, located in abundance on the surface of the calyx and to a lesser extent on leaves and stems [6,7]. The constituents of the essential oil of lavender have been well investigated and are found to consist mainly of monoterpenoids and sesquiterpenoids [8-13]. Although the reported percentages of the constituents vary widely, $(R)$-linalool and $(R)$-linalyl acetate are consistently described as the most abundant compounds (each 15-45\%). Other characteristic components that have been identified are $(R)$-limonene, 1,8-cineol, camphor, ter- 
50 pinen-4-ol, lavandulol, lavandulyl acetate and $\alpha$-terpineol $51 \quad[14,15]$.

$52 \mathrm{Q3}_{\wedge} \quad$ The first terpene synthase (TPS) ${ }^{1}$ genes were cloned 53 from tobacco and spearmint (Mentha spicata) $[16,17]$Their$_{\lambda}$ 54 sequence data have enabled the identification of related 55 genes from other species, e.g. from Arabidopsis thaliana 56 [18-22], Clarkia breweri [23], Abies grandis [24-26], Oci57 mum basilicum [27], Salvia officinalis [28], M. spicata [17], 58 Citrus limon [29] and Zea mays [30,31]. Interestingly, the 59 economically important lavender has not been investigated 60 in this regard, hampering improvement of essential oil pro61 duction by molecular biological techniques or classical 62 breeding. Here, we report the cloning and biochemical 63 characterization of two monoterpene synthases and one 64 sesquiterpene synthase that make substantial contributions 65 to the flavor of L. angustifolia essential oil.

\section{Materials and methods}

\section{Plant material and reagents}

Plants of 'true lavender' ( $L$. angustifolia) were purchased at a local market and grown indoors. Standard growing conditions were maintained at $25^{\circ} \mathrm{C}$ and a $16-\mathrm{h}$ photoperiod under $120 \mu \mathrm{mol} \mathrm{m} \mathrm{m}^{-2} \mathrm{~s}^{-2}$ irradiance provided by Osram Fluora lamps (München, Germany). Fresh leaves were cut and used directly in subsequent experiments. Lavender flowers were harvested from one L. angustifolia plant grown outside in a pot under natural conditions. Hyptis suaveolens plants were purchased from Rühlemanns Kräuter \& Duftpflanzen (Horstedt, Germany) and cultivated indoors for a few weeks as for the L. anfustifolia plants before use.

All chemicals and solvents were obtained from Sigma, Fluka and Aldrich (all Taufkirchen, Germany), Carl Roth (Karlsruhe, Germany) and VWR International (Darmstadt, Germany) unless otherwise noted. Geranyl diphosphate (GPP) was purchased from Echelon Biosciences (Salt Lake City, USA). Solvents were distilled using a Vigreux column prior to use.

DNA modifying enzymes were obtained from Fermentas (St. LeonRot, Germany) and New England Biolabs (Frankfurt am Main, Germany). Primer synthesis and sequencing was performed by MWGBiotech (Ebersberg, Germany). For isolation of DNA fragments from agarose gels the Perfectprep Gel Cleanup Kit (Eppendorf, Hamburg, Germany) was used, whereas plasmid DNA was prepared with the Wizard Plus SV Miniprep Kit (Promega, Mannheim, Germany).

\section{Cloning of partial terpene synthase sequences}

Protein sequences of linalool synthases from Artemisia annua (GenBank Accession No. AAF13356), Mentha citrata (AAL99381), Perilla frutescens (AAL38029), A. thaliana (AAO85533), Fragaria $\times$ ananassa $(\mathrm{CAD} 57106)$ and an $(E, E)$ - $\alpha$-farnesene synthase from Malus domestica (AAO22848) were aligned with ClustalW 1.83, revealing several conserved regions. Based on the sequences $\mathrm{F}(\mathrm{RK})(\mathrm{LI}) \mathrm{LRQ}(\mathrm{HE}) \mathrm{G}, \mathrm{E}(\mathrm{GD}) \mathrm{E}(\mathrm{DH}-$ $\mathrm{S})(\mathrm{TI}) \mathrm{L}$ and $\mathrm{DD}(\mathrm{VI})(\mathrm{YF}) \mathrm{D}(\mathrm{VI})(\mathrm{YF}) \mathrm{G}$ the degenerate forward primers TerpDeg1_FW (5'-T(AC)C T(GC)(AC) G(AG)C A(AG)C A(GT)G G-3'), TerpDeg2_FW (5'-GA(AG) G(AG)(AT) GAA (AG)(ACT)A $(\mathrm{CT})(\mathrm{AT})(\mathrm{CT})$ TIG-3' with I resembling inosine) and TerpDeg3_FW $\left(5^{\prime}-\mathrm{GA}(\mathrm{CT}) \mathrm{GA}(\mathrm{CT}) \quad(\mathrm{AG}) \mathrm{T}(\mathrm{CT}) \mathrm{T} \quad(\mathrm{AG})(\mathrm{CT}) \mathrm{G}\right.$ AT(AG) T(GCT)T (AT)TG G-3') were designed. The degenerate reverse primer TerpDeg4_REV (5'-ACC A(CT)T (GCT)(AT)G C(CT)T C(CT)(AT)

${ }^{1}$ Abbreviations used: TPS, terpene synthase; GPP, geranyl diphosphate; IPTG, isopropyl- $\beta$-D-thiogalactopyranoside; BSA, bovine serum albumine.
$\left.(\mathrm{GCT})(\mathrm{CT}) \mathrm{A}-3^{\prime}\right)$ is based on the peptide sequence $\mathrm{L}(\mathrm{VKQ}) \mathrm{EA}(\mathrm{KQE}) \mathrm{W}$. The primers TerpDeg5_FW (5'-ATG (CT)TI CA(AG) (CT)TI TA(CT) GA(AG) GC-3') and TerpDeg6_REV (5'-(CT)T(GT) CAT (AG)TA (AG)TC IGG IA(AG) I(CT)(GT) ITC-3') were taken from the literature exploiting other sequence similarities [32].

To generate cDNA, about $100 \mathrm{mg}$ of lavender flowers or leaves were frozen in liquid nitrogen and ground to a fine powder. Total RNA was extracted with the RNeasy Plant Mini Kit (Qiagen, Hilden, Germany) and further purified to mRNA with the Oligotex mRNA Mini Kit (Qiagen, Hilden, Germany). Reverse transcription was performed with Superscript III Reverse Transcriptase (Invitrogen, Karlsruhe, Germany) using the oligo(dT) anchor primer 5'-GCT GTC AAC GAT ACG CTA CGT AAC GGC ATG ACA GTG TTT TTT TTT TTT TTT TTT-3'. The resulting cDNA of flowers or leaves served as a template in subsequent PCRs with Taq DNA polymerase (New England Biolabs, Frankfurt am Main, Germany) and all combinations of sense and antisense degenerate primers. The temperature was programmed with a Primus 96 advanced thermocycler (Peqlab Biotechnologie, Erlangen, Germany) and started with 2 min at $94{ }^{\circ} \mathrm{C}$, followed by 33 cycles beginning at $94^{\circ} \mathrm{C}$ for $30 \mathrm{~s}$, annealing at $43{ }^{\circ} \mathrm{C}$ for $30 \mathrm{~s}$ and elongating at $72{ }^{\circ} \mathrm{C}$ for $20-90 \mathrm{~s}$ according to the expected length of the amplified fragment. PCR products revealing the approximate size of partial terpene synthase sequences by agarose gel electrophoresis were excised and extracted. A second PCR using the same primers directly or in a nested position yielded larger quantities of DNA that could be subcloned into the pGEM-T vector (Promega, Mannheim, Germany) for sequencing. The similarity of cloned sequences to known sequences was checked with NCBI pBLAST [33].

\section{Cloning of full-length terpene synthases}

The $3^{\prime}$-ends of the putative terpene synthases were amplified by $3^{\prime}$ RACE-PCR. A $25 \mu \mathrm{l}$ PCR mixture contained $1 \mu \mathrm{l}$ cDNA, $1 \mu \mathrm{l}$ dNTPs (10 $\mathrm{mM}), 1 \mu \mathrm{l}$ gene specific forward primer $(10 \mu \mathrm{M}), 1 \mu \mathrm{l}$ of the anchor binding primer $(10 \mu \mathrm{M}) \mathrm{GR}^{\prime}\left(5^{\prime}\right.$-GCT GTC AAC GAT ACG CTA CGT AAC G-3') or GR3'Nested (5'-CGC TAC GTA ACG GCA TGA CAG TG-3') (Invitrogen, Karlsruhe, Germany), $1 \mathrm{U}$ Taq DNA polymerase and appropriate amounts of recommended buffer and water. The primer combination for LaLIMS was 5'-AAA GTC GAT GAG AAT GGT GATG AT-3' and GR3', for LaLINS 5'-TGG CCA CCA AGA TCA TAA CCC TAA TCA C- $3^{\prime}$ and GR3'Nested, and for LaBERS $5^{\prime}$-CGT TAG AAG AAC TTC AAG AGT TCA CAG AG-3' and GR3'. The temperature was programmed according to a touchdown protocol, starting with 2 min at $94^{\circ} \mathrm{C}$, followed by 12 cycles with decreasing annealing temperature $\left(94{ }^{\circ} \mathrm{C}, 30 \mathrm{~s} ; 68^{\circ} \mathrm{C}\right.$ to $1{ }^{\circ} \mathrm{C} /$ cycle, $\left.30 \mathrm{~s} ; 72{ }^{\circ} \mathrm{C}, 1 \mathrm{~min} / \mathrm{kb}\right), 24$ standard cycles $\left(94^{\circ} \mathrm{C}, 30 \mathrm{~s} ; 55^{\circ} \mathrm{C}, 30 \mathrm{~s} ; 72{ }^{\circ} \mathrm{C}, 1 \mathrm{~min} / \mathrm{kb}\right)$ and a final elongation step $\left(72^{\circ} \mathrm{C}, 5 \mathrm{~min}\right)$. The amplified products were purified by gel electrophoresis, subcloned and sequenced.

To clone the $5^{\prime}$-ends of the transcripts (5'-RACE), cDNA was synthesized from mRNA with Superscript III Reverse Transcriptase and gene specific reverse primers based on the known sequence parts (LaLIMS: $5^{\prime}$ CTC AAA GGT TCC CAT TGC CCA GAA GTA-3'; LaLINS: $5^{\prime}$-TTC CAC AAG CCT ATC CCT CAC AAA TG-3'; LaBERS: $5^{\prime}$-CAA TGA ATT GAT ATC CCA TCT CTC G- $\left.3^{\prime}\right)$. The purified product $(14.6 \mu \mathrm{l})$ was incubated with $30 \mathrm{U}$ terminal deoxynucleotidyl transferase (Promega, Mannheim, Germany), $0.4 \mu \mathrm{ldATP}(10 \mathrm{mM})$ and $5 \mu \mathrm{l}$ of appropriate buffer at $37^{\circ} \mathrm{C}$ for $10 \mathrm{~min}$ to synthesize an oligo(dA)-tail, followed by an inactivation step at $70^{\circ} \mathrm{C}$ for $10 \mathrm{~min}$. This cDNA $(1 \mu \mathrm{l})$ was used as a template in PCR mixtures with a total volume of $25 \mu \mathrm{l}$, containing $1 \mu \mathrm{l}$ dNTPs $(10 \mathrm{mM}), 1 \mu \mathrm{l}$ oligo(dT) anchor primer as for $3^{\prime}$-RACE $(1 \mu \mathrm{M})$, $1 \mu \mathrm{l}$ gene specific reversed primer nested with the cDNA primer $(10 \mu \mathrm{M})$, $1 \mu \mathrm{l} \mathrm{GR} 3^{\prime}$ or GR3'Nested primer $(10 \mu \mathrm{M}), 1 \mathrm{U}$ Taq DNA polymerase and appropriate amounts of buffer and water. The primers used had the following sequences: $5^{\prime}$-CAG AAG TAG GAC TCA ACA ACC CG-3' and GR3' (LaLIMS), 5'-CGA TAT TGG CGT CAA TTC CAT CAC CAT CC- $3^{\prime}$ and GR3'Nested (LaLINS), $5^{\prime}$-CTC TGT GAA CTC TTG AAG TTC TTC TAA CG- $3^{\prime}$ and GR $3^{\prime}$ Nested (LaBERS). After an initial cycle for second strand synthesis $\left(94{ }^{\circ} \mathrm{C}, 2 \mathrm{~min} ; 50{ }^{\circ} \mathrm{C}, 2 \mathrm{~min} ; 72^{\circ} \mathrm{C}, 40 \mathrm{~min}\right)$ a touchdown protocol similar to that used for $3^{\prime}$-RACE-PCR was applied. 
The product was purified by gel electrophoresis and used as a template in a second PCR with the same primers to amplify the $5^{\prime}$-end of LaBERS in sufficient amounts. Single amplicons of all three terpene synthases showing the expected length of the $5^{\prime}$-terminal end were extracted from agarose gel, subcloned and sequenced.

The sequence information obtained by $3^{\prime}$ - and $5^{\prime}$-RACE-PCR was used to design primer pairs that anneal in the untranslated regions of the putative terpene synthases (LaLIMS: $5^{\prime}$-AAA ACC AAC TAC CCA TCA CAG AA- $3^{\prime}$ and $5^{\prime}$-GAG GTT ATT ACT TGA CTG AAC ATT GC-3'; LaLINS: 5'-ATA CAA AGA CAA ACC AAA CCA ACA AGC$3^{\prime}$ and $5^{\prime}$-TCA TAA CTT TGA TGA GGG AGA CAC-3'; LaBERS: 5'AGT GAG ATC CTC ATC TCA TCT CAG- $3^{\prime}$ and $5^{\prime}$-GTA GAA ATT AAG AAC AGG GAG TCT AC-3'). The full-length sequences were cloned from cDNA by PCR using proof-reading $P f u$ DNA polymerase (Promega, Mannheim, Germany). To this end $1 \mu \mathrm{l}$ cDNA (from leaf for cloning LaLIMS, from flower for LaLINS and LaBERS, $0.5 \mu \mathrm{l}$ dNTPs $(10 \mathrm{mM}), 1 \mu \mathrm{l}$ of each primer $(10 \mu \mathrm{M}), 0.5 \mathrm{U}$ Pfu DNA polymerase and appropriate quantities of buffer and water were initially incubated at $94{ }^{\circ} \mathrm{C}$ for $2 \mathrm{~min}$, followed by 30 cycles of denaturing, annealing and elongation $\left(94{ }^{\circ} \mathrm{C}, 30 \mathrm{~s}\right.$; primer melting temperature $\left.-5^{\circ} \mathrm{C}, 30 \mathrm{~s} ; 72^{\circ} \mathrm{C}, 4 \mathrm{~min}\right)$ and a final elongation step $\left(72^{\circ} \mathrm{C}, 5 \mathrm{~min}\right)$. The product was subcloned into pGEM-T and the resulting plasmid DNA was sequenced.

\section{Amplification from genomic DNA}

Genomic DNA was extracted from $100 \mathrm{mg}$ lavender leaves using the DNeasy Plant Mini Kit (Qiagen, Hilden, Germany). PCR was performed in a way analogous to the procedure for cloning the full-length sequences, but used genomic DNA instead of cDNA. The obtained amplicons were cloned into pGEM-T and sequenced stepwise. Pairwise alignment of DNA and mRNA sequences revealed the position and length of introns and exons, respectively. However, the numbers are approximated slightly due to identical nucleotides flanking both sides of several exons.

\section{Preparation of expression constructs}

To obtain recombinant GST fusion proteins for functional characterization, the terpene synthase sequences were cloned into the expression vector pGEX-4 T-1 (Amersham Biosciences, Freiburg, Germany). The open reading frames were amplified by PCR from plasmid DNA containing the full-length sequences. The primers generated overhangs to obtain restriction sites and to allow the cloning to proceed in frame with the vector sequence coding for the N-terminal GST moiety. The complete coding regions were amplified with $P f u$ DNA polymerase and with the following primers, thereby introducing the given restriction sites: $5^{\prime}$-CGG AAT TCA TGT CTA TCA TTA GCA TG-3' (EcoRI) and 5'-ATG CGG CCG CTT AGG GAT ATG GCT C-3' (NotI) for LaLIMS, 5'-GCG AAT TCA TGT CGA TCA ATA TCA ACA TGC-3' (EcoRI) and 5'CGG TCG ACT CAT GCG TAC GGC TCG-3' (SalI) for LaLINS, 5'-GCG AAT TCA TGG AGG CGA GAA GGT CG-3' (EcoRI) and 5'CGG TCG ACT CAT GGC ATA TGG AAG GGT AG-3' (SalI) for LaBERS. Additionally the 'pseudomature' forms of LaLIMS and LaLINS were generated by deleting the $5^{\prime}$-terminal nucleotides coding for plastidial transit peptides. The cleavage site was assumed to be just upstream of the twin arginine motif of terpene synthases [34]. The truncated sequence of LaLIMS, called LaLIMS_RR, was amplified starting from the codon of $\mathrm{Asp}^{56}$ immediately upstream of the arginines using the forward primer 5'-CGG AAT TCG ATG AAA CCC GAC GCT C-3' (EcoRI) and the reverse primer as before. The coding sequence of the 'pseudomature' LaLINS_RR starts with the first of the twin arginines $\mathrm{Arg}^{27}$ and was cloned employing the forward primer 5'-GCG AAT TCC GAC GCT CCG GAA ACT AC-3' (EcoRI). After subcloning into pGEM-T and digestion of plasmid DNA the sequences were ligated into the expression vector pGEX-4T-1 that was previously digested with the same enzymes. The expression vector was transformed into Escherichia coli JM109 cells (Promega, Mannheim, Germany), plasmid DNA was purified and sequenced to check for correct insertion.

\section{Heterologous expression and partial purification}

Expression constructs were transformed into E. coli Rosetta(DE3)pLysS cells (Novagen, Darmstadt, Germany). Single colonies of transformants were incubated overnight at $37^{\circ} \mathrm{C}$ and $120 \mathrm{rpm}$ in Luria-Bertani medium supplemented with ampicillin $(100 \mu \mathrm{g} / \mathrm{ml})$ and chloramphenicol $(34 \mu \mathrm{g} / \mathrm{ml})$. The following day the culture was diluted 1:40 with LB medium containing the antibiotics and grown under the same conditions as above to an $\mathrm{OD}_{600}$ of $0.4-0.8$. After inducing expression by adding isopropyl- $\beta$-Dthiogalactopyranoside (IPTG) to a final concentration of $1 \mathrm{mM}$ the culture was incubated at $16^{\circ} \mathrm{C}$ and $120 \mathrm{rpm}$. The next day cells were harvested by centrifugation $(5000 \mathrm{~g}, 15 \mathrm{~min})$ and subjected to a purification procedure using GST bind resin (Novagen, Darmstadt, Germany), following the manufacturer's protocol with slight modifications. All steps were performed at $4{ }^{\circ} \mathrm{C}$ with pre-chilled buffers to maintain enzyme activity. The harvested cells were frozen at $-80^{\circ} \mathrm{C}$ and thawed in $30 \mathrm{ml} \mathrm{GST}$ wash buffer (43 mM Na $2 \mathrm{HPO}_{4}, 14.7 \mathrm{mM} \mathrm{KH}_{2} \mathrm{PO}_{4}, 1.37 \mathrm{M} \mathrm{NaCl}, 27 \mathrm{mM} \mathrm{KCl}, \mathrm{pH} 7.3$ ) supplemented with $1 \mathrm{mM}$ proteinase inhibitor phenylmethanesulfonylfluoride. The freeze-thaw cycle supported cell disruption, which was further enhanced by subsequent sonication in three intervals of $30 \mathrm{~s}$ at $15 \%$ power (Sonopuls UW2200, Bandelin electronic, Berlin, Germany). The lysate was centrifuged $(10,000 \mathrm{~g}, 20 \mathrm{~min})$ and incubated for $30 \mathrm{~min}$ with GST bind resin previously equilibrated with GST wash buffer. After centrifugation $(800 \mathrm{~g}, 5 \mathrm{~min})$ the supernatant was discarded and the resin was washed three times with 10 volumes of GST wash buffer. Then the recombinant GST fusion protein was eluted in two volumes of $0.75 \mathrm{ml}$ GST elution buffer ( $50 \mathrm{mM}$ Tris- $\mathrm{Cl}, \mathrm{pH} 8.0,10 \mathrm{mM}$ reduced glutathione). For use in enzyme assays the two fractions were pooled. Protein concentration was determined by the photometric method of Bradford [35].

\section{Enzyme assays}

Standard assays were carried out in a total volume of $500 \mu$ l containing buffer (25 mM Tris-Cl, pH 7.5, 5\% glycerol, 1 mM DTT) supplemented with cofactors ( $10 \mathrm{mM} \mathrm{MgCl}, 1 \mathrm{mg} / \mathrm{ml} \mathrm{BSA}$; assays with LaLINS additionally $1 \mathrm{mM} \mathrm{MnCl}_{2}$ ), $50 \mu \mathrm{M}$ substrate (geranyl, farnesyl or geranylgeranyl diphosphate) and 2-20 $\mu \mathrm{g}$ purified recombinant enzyme. The mixture was overlaid with $500 \mu$ diethyl ether and incubated at $23{ }^{\circ} \mathrm{C}$ for 15 $10 \mathrm{~min}$. The reaction was stopped by vigorous mixing and centrifugation to separate phases. After addition of an internal standard (LaLIMS and LaBERS: $1 \mu \mathrm{g}$ camphor, LaLINS: $0.164 \mu \mathrm{g}\left[1,2-{ }^{2} \mathrm{H}_{2}\right]$-Linalool) the upper solvent phase was collected followed by a second extraction with $500 \mu \mathrm{l}$ diethyl ether. The combined extracts were reduced to approximately $300 \mu \mathrm{l}$ under a stream of nitrogen, dried with $\mathrm{Na}_{2} \mathrm{SO}_{4}$ and analyzed.

Optimum reaction temperature was determined in assays as before but with a reduced volume of $100 \mu \mathrm{l}$. Before adding the substrate the mixture was equilibrated to the tested temperature. Substitution of the Tris-buffer with buffers of different $\mathrm{pH}$ ( $25 \mathrm{mM}$ MES, MOPS, MOPSO, TAPS and CAPSO buffers ranging from $\mathrm{pH} 4-10$ ) allowed evaluation of the $\mathrm{pH}$ that enables the highest activity. For testing divalent cations the enzyme solution was desalted with PD-10 columns (Amersham Biosciences, Freiburg, Germany) and assayed in buffers containing between five and seven different concentrations of $\mathrm{MgCl}_{2}(1-500 \mathrm{mM})$ and $\mathrm{MnCl}_{2}(0.01-$ $10 \mathrm{mM}$ ). Negative controls were performed without supplying salts and with $1 \mathrm{mM}$ EDTA. Kinetic data was obtained in assays with seven different substrate concentrations $(1-200 \mu \mathrm{M})$ under optimum conditions. The Michaelis-Menten equation was determined by hyperbolic regression of the resulting data using the software SigmaPlot v.8.02 (Systat Software, Erkrath, Germany). Two technical replicates (same preparation) and at least two biological replicates (different preparations) were carried out. Controls were performed under the same conditions but using the purified product of the empty expression vector instead of enzyme solution.

\section{Product analysis}

The diethyl ether extracts obtained from the assays were analyzed with capillary gas chromatography-mass spectrometry to identify and to 
quantify the enzymatically formed products. An aliquot $(2 \mu \mathrm{l})$ was injected splitless into a Trace GC 2000 ultra (Thermo Finnigan, Egelsbach, Germany) equipped with a BPX5 column $\left(30 \mathrm{~m} \times 0.25 \mathrm{~mm}, d_{\mathrm{f}}=0.25 \mu \mathrm{m}\right)$ (SGE, Darmstadt, Germany). The gas chromatograph was coupled to a Thermo Finnigan Trace DSQ mass spectrometer operating with electron ionization (temperature of ion source $200^{\circ} \mathrm{C}$, electron energy $70 \mathrm{eV}$ ). The scan rate was set to $500 \mathrm{amu} / \mathrm{s}$. The injector was heated to $220^{\circ} \mathrm{C}$ and the GC oven was programmed with a temperature gradient starting at $40^{\circ} \mathrm{C}$ (5 min isothermal), ramping at $4{ }^{\circ} \mathrm{C} / \mathrm{min}$ to $240{ }^{\circ} \mathrm{C}$ ( $25 \mathrm{~min}$ isothermal) under the constant pressure ( $75 \mathrm{kPa}$ ) of a carrier gas (helium). Identity of monoterpenoid components was confirmed by comparison of mass spectra and retention times with authentic standards. Sesquiterpenes were tentatively identified by comparison of mass spectra with library data (NIST MS Search 2.0a) and of linear retention indices. For quantification a faster gradient was chosen, starting at $40{ }^{\circ} \mathrm{C}(1 \mathrm{~min}$ isothermal), increasing at $15^{\circ} \mathrm{C} / \mathrm{min}$ to $250^{\circ} \mathrm{C}$ ( $10 \mathrm{~min}$ isothermal). The temperature of the injector was set at $200^{\circ} \mathrm{C}$ and the carrier gas at a constant flow rate of $1.5 \mathrm{ml} / \mathrm{min}$. Concentrations of components were calculated using response factors.

To determine the enantiomeric distribution of the products, chiral gas chromatography was performed. The diethyl ether extracts were injected on-column to a chiral phase (33\% heptakis(2,3,6-tri- $O$-ethyl)- $\beta$-cyclodextrin in OV-1701-vi, $30 \mathrm{~m} \times 0.25 \mathrm{~mm}$ i.d., $0.25-\mu \mathrm{m}$ film thickness) in a GC 8000 series gas chromatograph (ThermoFinnigan, C.E. Instruments, Egelsbach, Germany) with a flame ionization detector set at $220^{\circ} \mathrm{C}$. The oven temperature was programmed from $40^{\circ} \mathrm{C}(2 \mathrm{~min}$ isothermal) to $50{ }^{\circ} \mathrm{C}$ at $2{ }^{\circ} \mathrm{C} / \mathrm{min}$, continuing with $1{ }^{\circ} \mathrm{C} / \mathrm{min}$ to $60^{\circ} \mathrm{C}$ and with $2{ }^{\circ} \mathrm{C} / \mathrm{min}$ to $200{ }^{\circ} \mathrm{C}$ ( $25 \mathrm{~min}$ isothermal). Hydrogen at a constant pressure of $100 \mathrm{kPa}$ was the carrier gas. Identification of products was performed by comparison of GC data to those of authentic reference compounds. The orders of elution of the enantiomers were determined by co-injection of optically pure reference compounds.

\section{Plant extracts}

Approximately $0.5 \mathrm{~g}$ of lavender flowers or $H$. $Q_{\Omega}$ leaves were vigorously mixed with $2 \mathrm{ml} n$-hexane. The mixture was centrifuged and the supernatant recovered. The extract was then concentrated to a volume of $500 \mu \mathrm{l}$ and analyzed by gas chromatography-mass spectrometry.

\section{Results and discussion}

\section{Cloning of terpene synthases}

Newly designed primers were used along with published primers in PCRs run with cDNA previously transcribed from mRNA of leaves and flowers from $L$. angustifolia [32]. The combinations of TerpDeg5_FW/TerpDeg6_REV and TerpDeg3_FW/TerpDeg6_REV were the most successful, yielding two partial sequences 582 and $108 \mathrm{bp}$ in length, both from leaf cDNA and flower cDNA. The transcripts from leaf were identical and designated LaLIMS, those from flower LaLINS and LaBERS, respectively. As the partial sequences were similar to terpene synthase genes reported in GenBank, the 5'- and 3'-ends were cloned by RACE-PCR to get the full-length sequences.

\section{Sequence analysis}

The open reading frames of LaLIMS, LaLINS and LaBERS consist of 1809,1695 and $1617 \mathrm{bp}$, coding for proteins with 602, 564 and 538 amino acids, respectively. The molecular masses are predicted to be 70.3, 65.8 and $62.4 \mathrm{kDa}$. Alignment of the three deduced protein sequences revealed between $40 \%$ (LaBERS compared to LaLIMS or LaLINS) and 60\% (LaLIMS and LaLINS) identity among the sequences (Fig. 1). Two characteristic motives of terpene synthases, DDXXD and $(\mathrm{N}, \mathrm{D}) \mathrm{D}(\mathrm{L}, \mathrm{I}, \mathrm{V}) \mathrm{X}(\mathrm{S}, \mathrm{T}) \mathrm{XXXE}$, are completely conserved in all three sequences. They are responsible for the coordination of divalent cations and thus are essential for substrate binding and ionization [36,37]. The N-terminal peptide sequence $\mathrm{RR}(\mathrm{X})_{8} \mathrm{~W}$, which is essential for the enzymatic activity of many monoterpene synthases, is also present [34]. Another characteristic element frequently found in such enzymes is LQLYEASFLL. Thought to be part of the active site, this element is conserved in LaLIMS and slightly altered in LaLINS and LaBERS $[28,38]$. The biggest differences between the lavender clones are located upstream of the $\mathrm{RR}(\mathrm{X})_{8} \mathrm{~W}$ motif. Whereas LaBERS contains only 3 more amino acids at the N-terminus, LaLIMS and LaLINS have an appendage of 58 and 26 amino acids. Comparatively many serine and alanine residues and few acidic amino acids are integrated in this part. This feature is often found in signal peptides, which direct proteins to plastids where they are processed to their active mature forms by truncation of the N-terminal peptides $[39,40]$. LaLIMS and LaLINS both contain such a plastidial signal peptide. This is consistent with the idea that they are monoterpene synthases, as the substrate geranyl diphosphate is synthesized in plastids, or more specifically, in the leucoplasts of the oil glands [41]. In contrast, LaBERS appears to be a sesquiterpene synthase remaining in the cytosol, where the cellular pool of farnesyl diphosphate is located. However, the signal peptide of LaLINS is short compared to the signal peptide of other monoterpene synthases that usually contain 50-70 amino acids [42].

Analysis of the genomic structure revealed no significant differences to previously characterized angiosperm terpene synthase genes. Trapp and Croteau [43] classified the genes by the number of introns, which were reduced by the time of evolution. Like other mono- and sesquiterpene synthases the three lavender genes contain six introns and accordingly belong to class III, the evolutionarily youngest class (Table 1). The lengths of introns vary considerably, but the positions are quite constant, as calculated from the 3 '-end of the mRNA sequences.

\section{Heterologous expression}

The full length sequences of LaLIMS, LaLINS and LaBERS were cloned into the pGEX4T-1 expression vector resulting in fusion proteins with N-terminal GST. Additionally, LaLIMS and LaLINS were expressed without signal peptides because the 'pseudomature' forms of other monoterpene synthases exhibited different kinetic properties [34]. As there were indications that the cleavage site in vivo is immediately upstream of the $\mathrm{N}$-terminal $\mathrm{RR}(\mathrm{X})_{8} \mathrm{~W}$ motif, the shortened version of LaLIMS, called LaLIMS_RR, was expressed starting with $\mathrm{Asp}^{56}$ and LaLINS_RR with $\mathrm{Arg}^{27}$. After IPTG-induced expression 


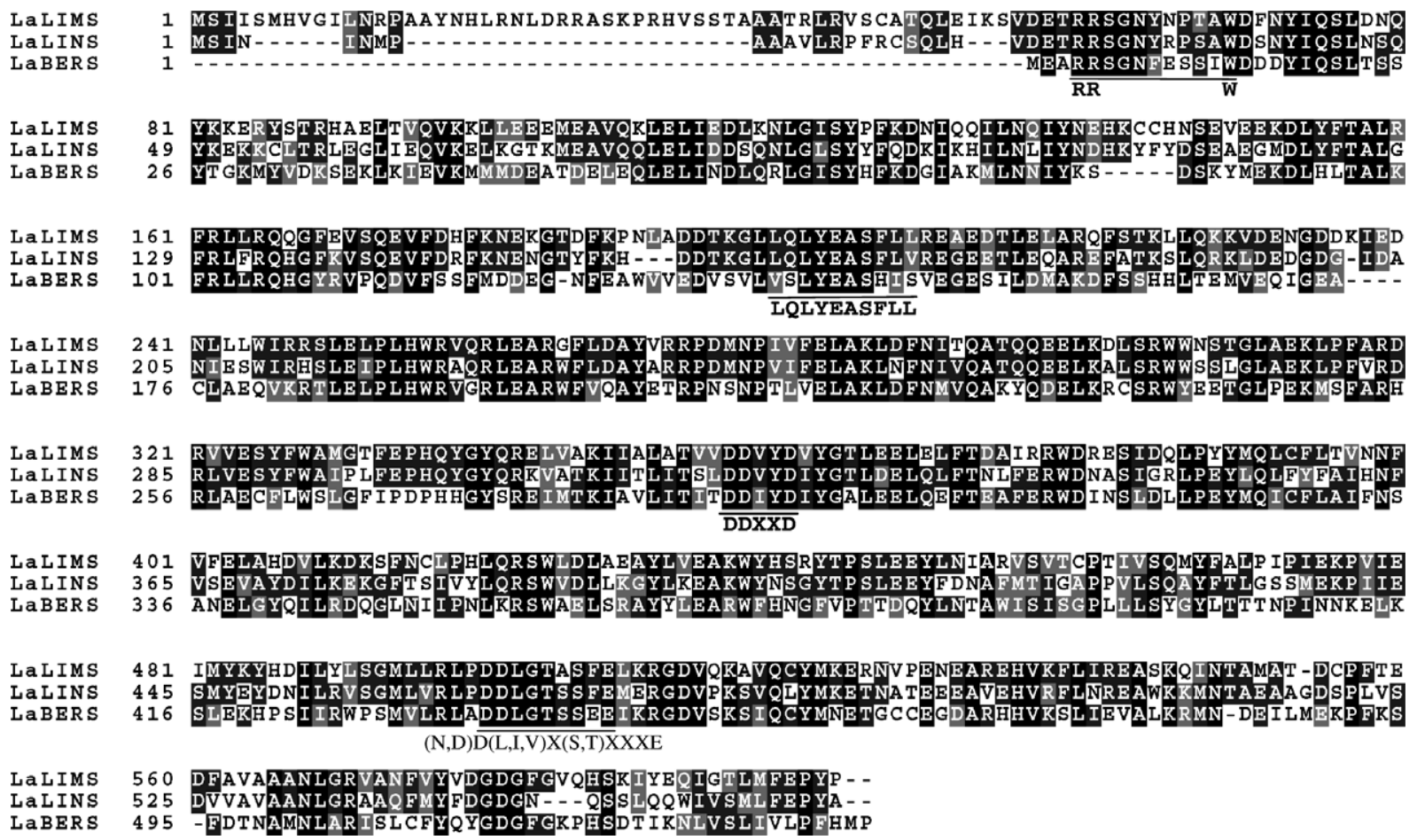

Fig. 1. Amino acid sequence alignment of the three cloned terpene synthases from Lavandula angustifolia. The sequences were aligned using the ClustalW program. Consensus amino acids are shaded. The four conserved regions of terpene synthases are underlined.

Table 1

Q4 Genomic structure of LaLIMS, LaLINS and LaBERS showing the length of all introns and exons in bp

\begin{tabular}{|c|c|c|c|c|c|c|c|c|c|c|c|c|c|c|c|}
\hline ron & tron & 1 & III & 2 & VIII & 3 & XI & 4 & XII & 5 & XIII & 6 & XIV & 7 & Total \\
\hline LI & & $246(82)$ & 65 & 2 & 81 & 32) & 105 & 210 & 82 & 138 & 105 & & 7 & & 321 \\
\hline LI & & $148(49)$ & 926 & 27 & 339 & 377 (126) & 93 & 22 & 148 & 139 & 78 & 249 & 435 & 4) & 3714 \\
\hline
\end{tabular}

Not all numbers could be accurately determined, because identical sequence elements are flanking both sides of some exons. The number of amino acids (in parenthesis) is rounded, as some introns interrupt triplets. Introns are numbered according to [43].

in $E$. coli the recombinant proteins were purified by affinity chromatography with GST Sepharose. Analysis by SDSPAGE showed that sufficient amounts of soluble protein were formed for all constructs except for the full-length protein of LaLIMS (data not shown). The signal peptide caused the formation of insoluble inclusion bodies, a common problem encountered by bacterial expression of monoterpene synthases [42].

\section{Characterization of a $(R)$-limonene synthase}

The 'pseudomature' form LaLIMS_RR revealed activity with geranyl diphosphate, but not with farnesyl diphosphate, nor with geranylgeranyl diphosphate. LaLIMS_RR synthesized six monoterpenes, limonene $(39 \%)$, terpinolene $(22 \%)$, camphene $(16 \%), \alpha$-pinene $(14 \%), \beta$-myrcene $(8 \%)$ and $\alpha$-phellandrene (1\%) (Fig. 2a). Chiral phase capillary gas chromatography demonstrated the preferential formation of the $(+)$-enantiomers $(1 R, 5 R)-(+)-\alpha$-pinene $(94 \%$ enantiomeric purity), $(1 R, 4 S)-(+)$-camphene $(96 \%)$ and $(R)-(+)$-limonene $(78 \%)$ (Fig. 3b). The concentration of the fourth chiral component, $\alpha$-phellandrene, was too low to allow accurate calculations of enantiomeric ratios. Low product specificity is a common characteristic of monoterpene synthases, which may explain why the abundance of different monoterpenes in the essential oil does not pose too high a cost for protein synthesis in the plant $[18,24,28,20,27]$.

The optimum temperature and $\mathrm{pH}$ range of the enzymatic reaction was determined in additional experiments. All extracts were analyzed by GC-MS, whereby each of the six products of LaLIMS_RR was individually quantified. The total amount of product peaked at $30^{\circ} \mathrm{C}$ and pH 7 (Fig. 4a and b). The amounts of most of the individual products followed this pattern, except for $\alpha$-pinene formation, which peaked at $33{ }^{\circ} \mathrm{C}$ and $\mathrm{pH} 6$. Because terpene synthases require divalent cations for activity, the effect of varying concentrations of $\mathrm{Mg}^{2+}(0-500 \mathrm{mM})$ and $\mathrm{Mn}^{2+}$ $(0-5 \mathrm{mM})$ was tested with a desalted solution of LaLIMS_RR (Fig. 4c and d). The total amount of products reached a maximum at concentrations of $50 \mathrm{mM} \mathrm{Mg}^{2+}$ and $0.2 \mathrm{mM} \mathrm{Mn}^{2+}$, while higher concentra- 
a

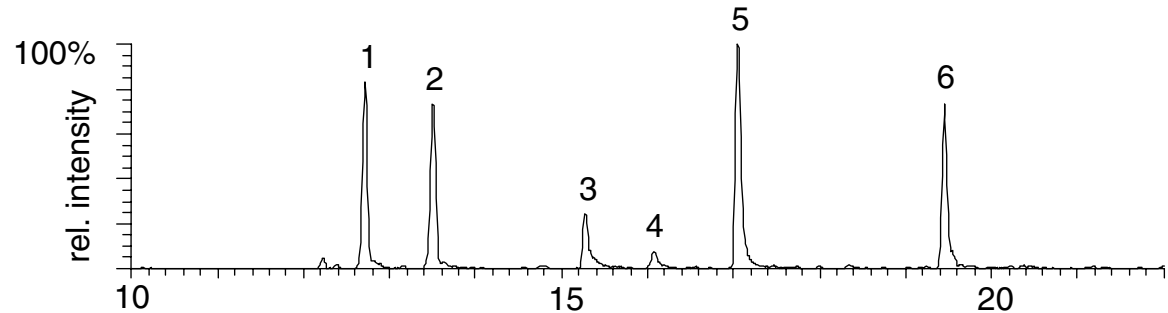

b

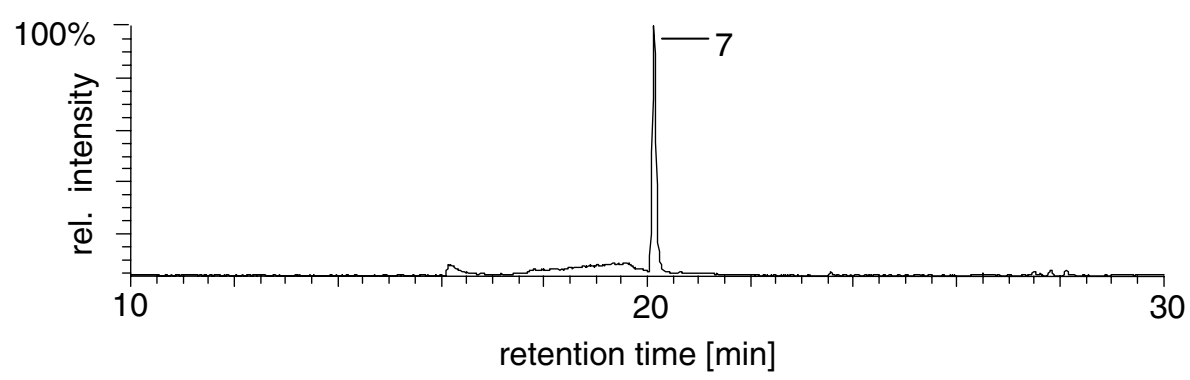

C<smiles>C=CC(=C)CCC=C(C)C</smiles>
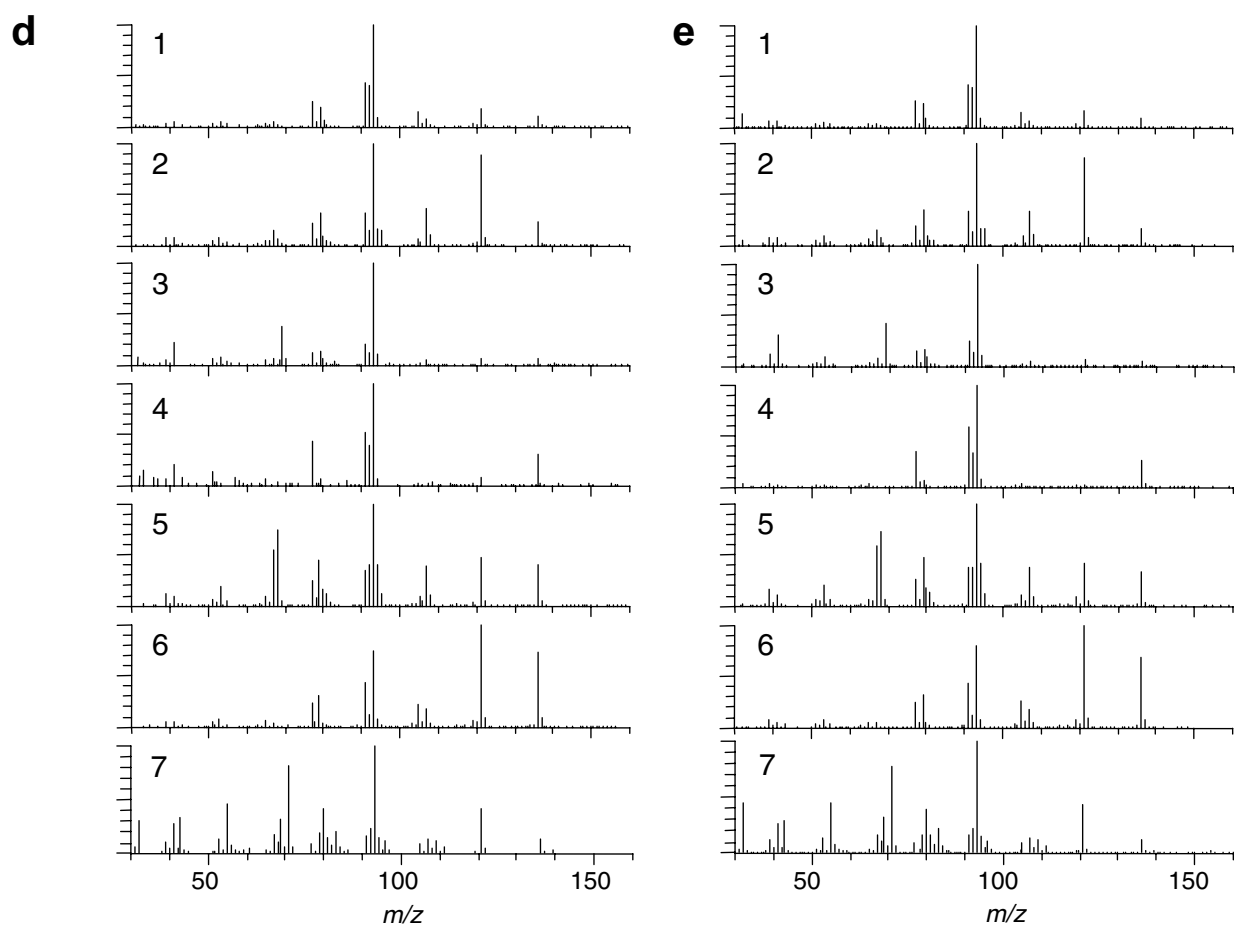

Fig. 2. (a) GC-MS analysis (ion chromatogram $\mathrm{m} / \mathrm{z}$ 93) of a diethyl ether extract obtained from assays with LaLIMS_RR and geranyl diphosphate. Comparison of mass spectra and retention times with those of authentic standards led to the identification of $\alpha$-pinene (1), camphene (2), $\beta$-myrcene (3), $\alpha$-phellandrene (4), limonene (5) and terpinolene (6). (b) GC-MS analysis (total ion chromatogram) of a diethyl ether extract obtained from assays with LaLINS and geranyl diphosphate showing linalool as the sole product. (c) Chemical structures of $(1 R, 5 R)-(+)$ - $\alpha$-pinene $(1),(1 R, 4 S)-(+)$-camphene $(2)$, $\beta$-myrcene (3), $(R)-(-)-\alpha$-phellandrene $(4),(R)-(+)$-limonene (5), terpinolene $(6)$ and $(R)-(-)$-linalool (7). All depicted enantiomers except for $\alpha$-phellandrene were determined by chiral analysis (Fig. 3). (d) Mass spectra of the products produced by LaLIMS_RR and LaLINS. (e) Mass spectra of authentic reference compounds. 

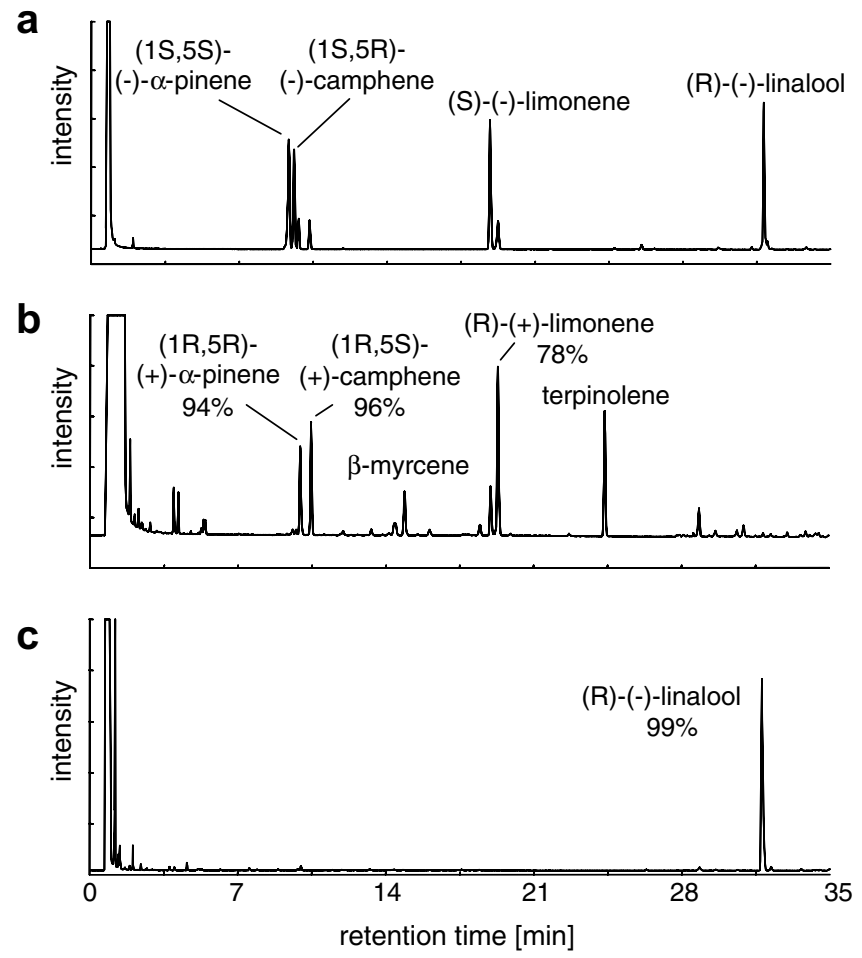

Fig. 3. Chiral phase gas chromatography (flame ionization detection). (a) Authentic standards with excess of the denoted enantiomers. The separation of the linalool enantiomers was shown in a separate run with racemic linalool (data not shown). (b) Analysis of a diethyl ether extract obtained from assays with LaLIMS RR and geranyl diphosphate. Percentages of the more abundant enantiomers are given. (c) Separation of the enantiomers of linalool extracted from assays with LaLINS and geranyl diphosphate.

tions caused a loss of activity. Manganese cations are not as effective as magnesium reaching only $68 \%$ of the highest product concentrations. The product pattern changed markedly to $46 \%$ limonene, $9 \%$ terpinolene, $23 \% \alpha$-pinene, $5 \% \beta$-myrcene and $4 \% \alpha$-phellandrene, when $\mathrm{Mn}^{2+}$ was supplied instead of $\mathrm{Mg}^{+}$. The percentage of $\alpha$-pinene almost doubled, while that of terpinolene was reduced by more than half. Also the product profile of monoterpene synthases purified from $S$. officinalis and Thymus vulgaris changed depending on the supplemented cation $[44,45]$. While these findings might be explained by the activity of co-purified enzymes, a heterologously expressed sesquiterpene synthase from $Z$. mays showed a similar effect [31]. This change may be due to the influence the divalent cations have on the three-dimensional structure of the active site and in coordinating the substrate diphosphate [37]. In the presence of $\mathrm{Mn}^{2+}$ the active site of LaLIMS is apparently changed in a manner that promotes the reaction cascade from the terpinyl cation to $\alpha$-pinene. Similarly, the $\mathrm{pH}$ may influence the form of the active site by changing the electrochemical properties of the residues. This would explain the elevated formation of $\alpha$-pinene at lower $\mathrm{pH}$.

The kinetic parameters of LaLIMS_RR were determined by incubation with substrate concentrations between 0 and $200 \mu \mathrm{M}$ at the optimum conditions of $30^{\circ} \mathrm{C}, \mathrm{pH} 7$ and $50 \mathrm{mM} \mathrm{Mg}^{2+}$. The reaction was stopped after $15 \mathrm{~min}$, which is in the linear range previously verified for a period of up to $180 \mathrm{~min}$ (Fig. 4e). The kinetic constant $K_{\mathrm{m}}=47.4 \pm 3.8 \mu \mathrm{M}$ and the maximum velocity $V_{\max }=133 \pm 4.0 \mathrm{pk} k_{\text {cat }} / \mathrm{mg}$ (Fig. 4f and Table 2) were calculated from the resulting hyberbolic curve, and the catalytic efficiency $k_{\text {cat }} / K_{\mathrm{m}}$ was $2.55 \times 10^{-4} 1 /(\mathrm{s} \mu \mathrm{M})$. Most other monoterpene synthases have exhibited lower $K_{\mathrm{m}}$ values, which indicate they have higher affinities to geranyl diphosphate than LaLIMS_RR [6].

\section{Characterization of a $(R)$-linalool synthase}

LaLINS accepted a single substrate - geranyl diphosphate - and transformed it to a single product-linalool (Fig. 2b). Farnesyl diphosphate and geranylgeranyl diphosphate were not transformed. Chiral phase gas chromatography showed that linalool synthase produced $(R)$-linalool with an enantiomeric purity of $98.5 \%$. This enantiomeric distribution is in agreement with the composition of the essential oil of $L$. angustifolia, which contains $(R)$-linalool with more than $94 \%$ enantiomeric purity and $(R)$-linalyl acetate (99\% enantiomeric purity) [8]. Since linalool, the sole product of LaLINS, along with linalyl acetate are the most abundant and characteristic components of lavender oil, and since enantiomeric distribution can be used as an indicator for the authenticity of the oil, it is very likely that the activity of LaLINS has a considerable impact on lavender flavor.

The dependence of LaLINS on temperature and $\mathrm{pH}$ is quite similar to LaLIMS with optimum activity at $30^{\circ} \mathrm{C}$ and $\mathrm{pH} 7$ (Table 2). In contrast to LaLIMS, $\mathrm{Mn}^{2+}$ was the preferred cation for LaLINS, which produced the highest yields at $1 \mathrm{mM}$, whereas $\mathrm{Mg}^{2+}$ was most effective at $50 \mathrm{mM}$ where it reached only $36 \%$ of the maximum $(R)$-linalool concentration. Kinetic analysis was performed with LaLINS and its 'pseudomature' form LaLINS RR. Both the kinetic constant $K_{\mathrm{m}}$ and the maximum velocity $V_{\max }$ were higher with the truncated version. However, the catalytic efficiency was higher with $1.34 \times 10^{-3} 1 /(\mathrm{s} \mu \mathrm{M})$ compared to $9.11 \times 10^{-4} 1 /(\mathrm{s} \mu \mathrm{M})$ of the premature LaLINS. An increase of activity for the truncated version was also reported for other monoterpene synthases suggesting that they are similar to the native mature forms [34]. The relatively high values for $K_{\mathrm{m}}$ (LaLINS: $42.7 \pm 4.6 \mu \mathrm{M}$; LaLINS_RR: $55.8 \pm 4.1 \mu \mathrm{M}$ ) were also described for a linalool synthase from M. citrata [46]. There, the authors showed that the kinetic constant of this enzyme was $56 \mu \mathrm{M}$, when bovine serum albumine (BSA) was added to the assays. In our experiments, we also supplied BSA because it had a stabilizing effect on activity.

\section{Characterization of a trans- $\alpha$-bergamotene synthase}

The third cloned enzyme, LaBERS, was active with farnesyl diphospate and, to a much lesser extent, with geranyl diphosphate as analyzed by GC-MS (Fig. 5a 

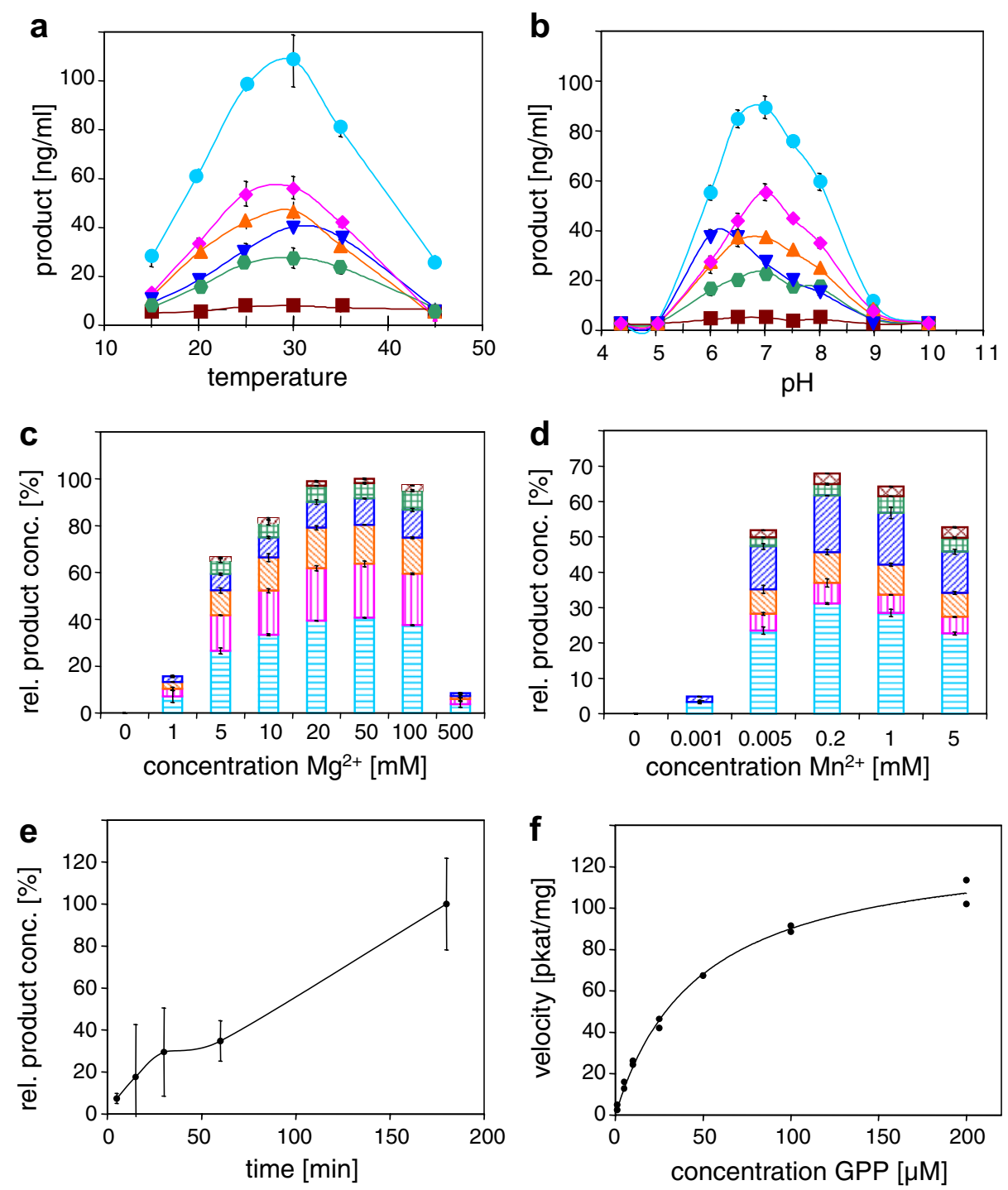

Fig. 4. Biochemical data of LaLIMS_RR. (a-d) The purified enzyme was incubated with geranyl diphosphate at different temperatures (a), pH values (b), concentrations of $\mathrm{Mg}^{2+}$ (c) and $\mathrm{Mn}^{2+}$ (d). The relative concentrations of each compound ( $\bullet$ 目 limonene, $\bullet$ 四 terpinolene, $\Delta \square$ camphene, $\nabla \square \alpha$-pinene, $\bullet$ 回 $\beta$ myrcene, $\alpha \alpha$-phellandrene) were determined by gas chromatography-mass spectrometry, showing dependence on the tested conditions. (e) Formation of the products was analyzed after different reaction periods to check for the linear range of the enzymatic reaction. (f) For kinetic analysis seven different concentrations of geranyl diphosphate $(1-200 \mu \mathrm{M})$ were incubated with LaLIMS_RR under optimum conditions. The velocity of total product formation was measured by GC-MS analysis allowing the calculation of the Michaelis-Menten equation by hyperbolic regression.

Table 2

Biochemical data of the characterized terpene synthases

\begin{tabular}{|c|c|c|c|c|c|}
\hline & LaLIMS_RR + GPP & LaLINS + GPP & LaLINS_RR + GPP & LaBERS + FPP & LaBERS + GPP \\
\hline$\overline{\mathrm{pH}}$ & 7.0 & 7.0 & - & 8.0 & - \\
\hline Temperature & $30^{\circ} \mathrm{C}$ & $30^{\circ} \mathrm{C}$ & - & $30{ }^{\circ} \mathrm{C}$ & $\sqrt{-}$ \\
\hline $\mathrm{Mg}^{2+}$ conc. & $50 \mathrm{mM}$ & $10-50 \mathrm{mM}(36 \%)$ & - & $50 \mathrm{mM}$ & $\Delta$ \\
\hline $\mathrm{Mn}^{2+}$ conc. & $0.2 \mathrm{mM}(68 \%)$ & $1 \mathrm{mM}$ & - & $0.05 \mathrm{mM}(49 \%)$ & \\
\hline$K_{\mathrm{m}}[\mu \mathrm{M}]$ & $47.4 \pm 3.8$ & $42.7 \pm 4.6$ & $55.8 \pm 4.1$ & $4.7 \pm 0.6$ & $3.3 \pm 0.3$ \\
\hline$V_{\max }\left[\mathrm{p} k_{\text {cat }} / \mathrm{mg}\right]$ & $133 \pm 4.0$ & $422 \pm 17$ & $837 \pm 25$ & $358 \pm 12$ & $2.9 \pm 0.1$ \\
\hline$k_{\text {cat }}[1 / \mathrm{s}]$ & $1.2 \times 10^{-2}$ & $3.9 \times 10^{-2}$ & $7.5 \times 10^{-2}$ & $3.3 \times 10^{-2}$ & $2.6 \times 10^{-4}$ \\
\hline$k_{\mathrm{cat}} / K_{\mathrm{m}}[1 /(\mathrm{s} \mu \mathrm{M})]$ & $2.6 \times 10^{-4}$ & $9.1 \times 10^{-4}$ & $1.3 \times 10^{-3}$ & $6.7 \times 10^{-3}$ & $7.8 \times 10^{-5}$ \\
\hline
\end{tabular}

The percentages in parenthesis are activities relative to the maximum activities obtained with the other divalent cation.

and c). Incubation with geranylgeranyl diphosphate did not yield any product. Thus, LaBERS is a sesquiterpene synthase with a side activity synthesizing monoterpenes.
The produced sesquiterpenes were tentatively identified by comparison of mass spectra with a database (NIST MS Search 2.0) and of linear retention indices with pub- 


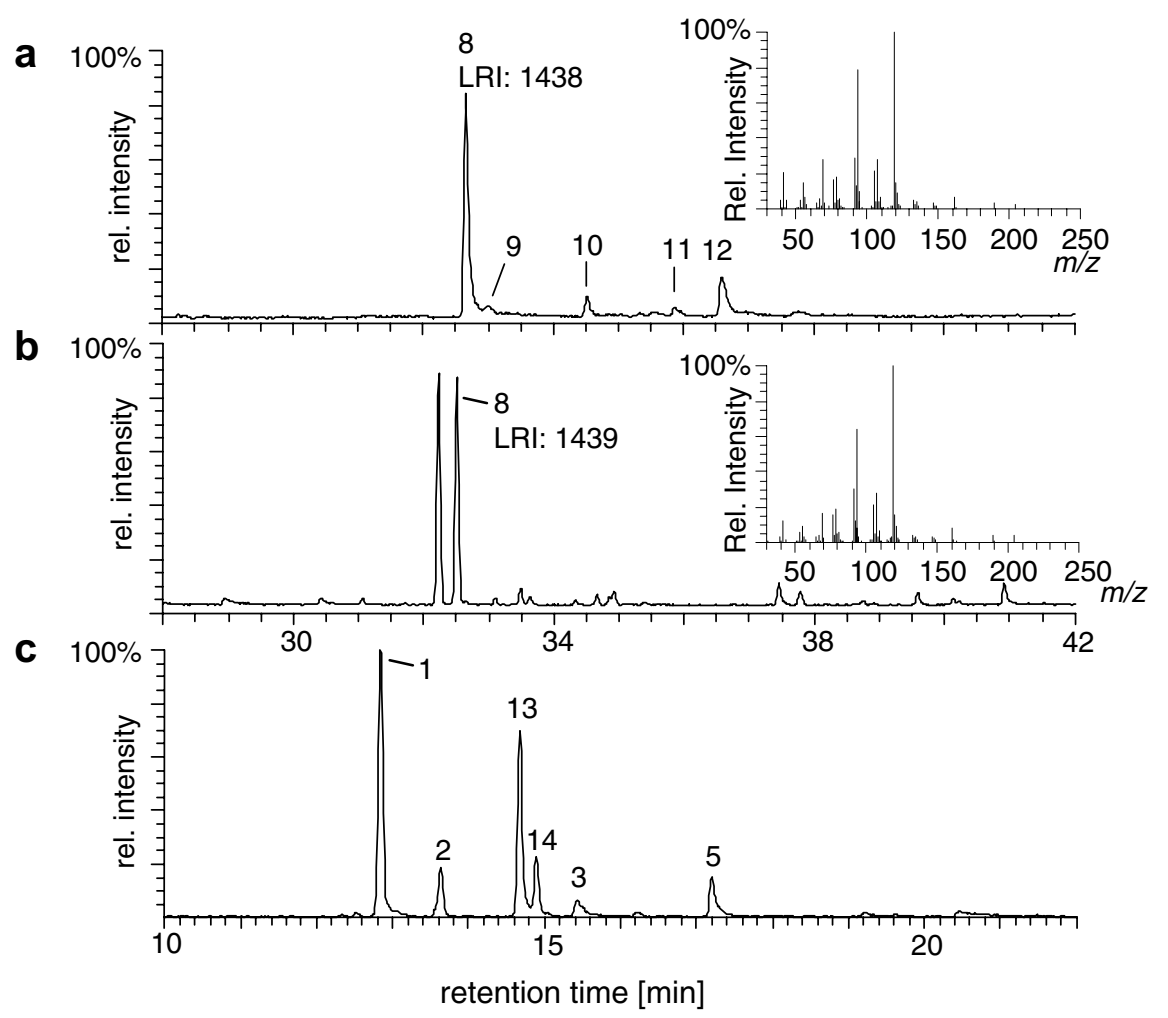

d
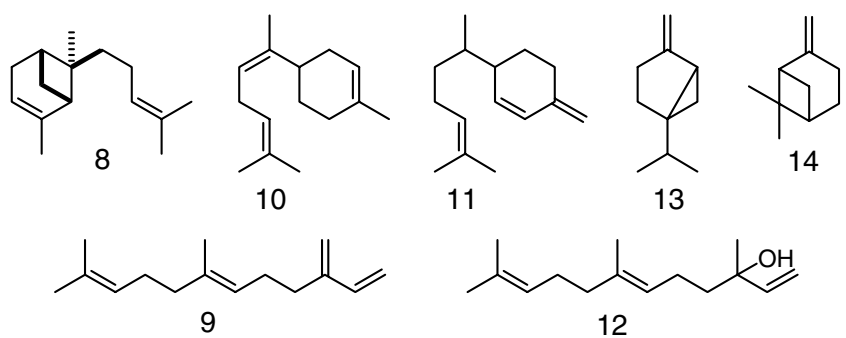

Fig. 5. (a) GC-MS analysis (total ion chromatogram) of a diethyl ether extract obtained by incubation of LaBERS with farnesyl diphosphate. The identities of the sesquiterpenes trans- $\alpha$-bergamotene (8), (E)- $\beta$-farnesene (9), $(Z)$ - $\alpha$-bisabolene (10), $\beta$-sesquiphellandrene (11) and $(E)$-nerolidol (12) were determined by comparison to a mass spectral database and linear retention indices (LRI). Inset shows the mass spectrum of the major peak 8. (b) Identity of trans- $\alpha$-bergamotene was additionally confirmed by analyzing an extract from leaves of Hyptis suaveolens, which contain large amounts of this sesquiterpene. The mass spectrum of trans- $\alpha$-bergamotene (8) is shown in the inset. Other peaks show additional compounds that are also produced by H. suaveolens leaves. (c) GC-MS analysis (ion chromatogram $\mathrm{m} / \mathrm{z} 93$ ) of a diethyl ether extract obtained by incubation of LaBERS with geranyl diphosphate. The monoterpenes $\alpha$-pinene (1), camphene (2), sabinene (13), $\beta$-pinene (14), $\beta$-myrcene (3) and limonene (5) were identified by comparing retention times and mass spectra to those of authentic standards. (d) Chemical structures of the identified compounds (numbers 8 to 12 ), showing trans- $\alpha$ bergamotene (8), (E)- $\beta$-farnesene (9), (Z)- $\alpha$-bisabolene (10), $\beta$-sesquiphellandrene (11), (E)-nerolidol (12), sabinene (13) and $\beta$-pinene (14). The structures of compounds $1-7$ are depicted in Fig. 2.

lished data [47-49]. Accordingly, LaBERS transforms farnesyl diphosphate mainly into trans- $\alpha$-bergamotene $(74 \%)$ and to lesser amounts of $(E)$-nerolidol $(10 \%)$, $(Z)$ - $\alpha$-bisabolene $(6 \%),(E)$ - $\beta$-farnesene $(5 \%)$ and $\beta$-sesquiphellandrene $(5 \%)$. Identity of trans- $\alpha$-bergamotene $(74 \%)$ was confirmed by analyzing an extract from leaves of $H$. suaveolens. The essential oil of this plant contains large amounts of this sesquiterpene and of caryophyllene, which can be clearly identified in the extract (Fig. 5b) [47]. Mass spectra and retention time of trans- $\alpha$-bergamotene from this source was identical to that produced by LaBERS. Incubating the enzyme with GPP yielded low concentrations of $\alpha$-pinene $(30 \%)$, sabinene $(27 \%)$, limo- nene $(17 \%), \beta$-pinene $(11 \%)$, camphene $(8 \%)$ and $\beta$-myrcene $(7 \%)$, which were identified by comparison with authentic standards.

LaBERS is the first reported enzyme that predominantly catalyzes the formation of trans- $\alpha$-bergamotene. Two enzymes (TPS4 and TPS5) from $Z$. mays that are closely related to each other showed broad product specificities and synthesized small proportions of trans- $\alpha$-bergamotene similar to an $(E)$ - $\beta$-farnesene synthase from the same species and an $\alpha$-zingiberene synthase from $O$. basilicum $[27,31,50]$.

Like the other terpene synthases discussed here, the optimum temperature for LaBERS was $30^{\circ} \mathrm{C}$, but its activity 
was highest at $\mathrm{pH} 8$ (Table 2). Product formation was greatest in the presence of the cofactor $\mathrm{Mg}^{2+}$ with product concentration peaking at $50 \mathrm{mM}$. Supplying the assays with $\mathrm{Mn}^{2+}$ showed highest activity at $0.05 \mathrm{mM}$ with $49 \%$ of the maximum product level. Kinetic data were determined for farnesyl diphosphate as well as geranyl diphosphate. BSA had a stabilizing effect and was added to the assays. Only the amounts of the main products trans- $\alpha-$ bergamotene and $\alpha$-pinene plus sabinene were measured, because the concentrations of the other components were too low for quantification. The $K_{\mathrm{m}}$ values were 10 -fold lower than those of LaLIMS and LaLIMS with $4.7 \pm 0.6 \mu \mathrm{M}$ farnesyl diphosphate and $3.3 \pm 0.3 \mu \mathrm{M}$ geranyl diphosphate, indicating better substrate affinity. The catalytic efficiency $k_{\text {cat }} / K_{\mathrm{m}}$ for the formation of sesquiterpenes was $6.74 \times 10^{-3} 1 /(\mathrm{s} \mu \mathrm{M})$, that of monoterpenes $7.76 \times 10^{-5} 1 /(\mathrm{s} \mu \mathrm{M})$. This low side activity with geranyl diphosphate is unlikely to be important in vivo, because LaBERS does not contain a signal peptide. Therefore it cannot be directed to the plastids where the pool of this substrate is located.

\section{Analysis of lavender flowers}

To estimate the role the three cloned enzymes play in the production of lavender oil, a hexane extract from flowers of L. angustifolia was prepared and analyzed by GC-MS (Fig. 6). The chromatogram confirmed the composition of lavender oil as described in the literature based on the abundant components [4,11]. The extract contained all products formed by LaLIMS, LaLINS and LaBERS except for the minor LaBERS products $(E)$-nerolidol, $(Z)$ - $\alpha$-bisabolene and $(E)$ - $\beta$-farnesene. These components may not be detected because they are metabolized in vivo or alternatively, because they are only produced in vitro because the recombinant proteins are slightly different from the native ones [27]. In any case, the products produced by LaLIMS, LaLINS and LaBERS account for more than $50 \%$ of the total peak areas in the chromatogram, if linalyl acetate $(14 \%$ of the area) is included in the calculation. However, the true impact of these enzymes in vivo can only be evaluated by the analysis of knock-out plants. Other important components of the lavender extract are 1,8-cineole, camphor, borneol, terpinen-4-ol, $\beta$-caryophyllene and germacrene-D, accounting for $30 \%$ of the total area (Fig. 6). Since these compounds are not synthesized by the three lavender terpene synthases described here, it seems additional terpene synthases must be present in $L$. angustifolia.

\section{Phylogenetic analysis}

The sequences of LaLIMS, LaLINS, LaBERS and 49 biochemically characterized terpene synthases from 30 species were analyzed with ClustalW. A phylogenetic tree was calculated by the neighbour-joining method and rooted to the subgroup TPS-c, which was defined as the out-group (Fig. 7). The seven classes of terpene synthases, that have been designated TPS-a to $-\mathrm{g}$, are clearly separated [24,51]. The three cloned lavender sequences all group in TPS-b, which predominantly contains monoterpene synthases from angiosperms. The most related sequences are all derived from plants that are members of the family Lamiaceae like lavender. It is known that terpene synthases of the same species are generally more related to each other than to enzymes with the same product specificity [52]. However, with the increasing number of characterized sequences, a weak sequence-function relation within a plant family is starting to emerge. LaLIMS produces several monoterpenes with similar structures, like its most related enzymes, while the trans- $\alpha$-bergamotene synthase LaBERS shares closest identity with the only other sesquiterpene cyclase of the TPS-b class. The phylogenetically nearest sequence to LaLINS is the linalool synthase from M. citrata (63\% identical to LaLINS), which also produces (R)-linalool [46].

The other known $(R)$-linalool synthases from $O$. basilicum [27] and A. annua [53] as well as the (S)-linalool syn-

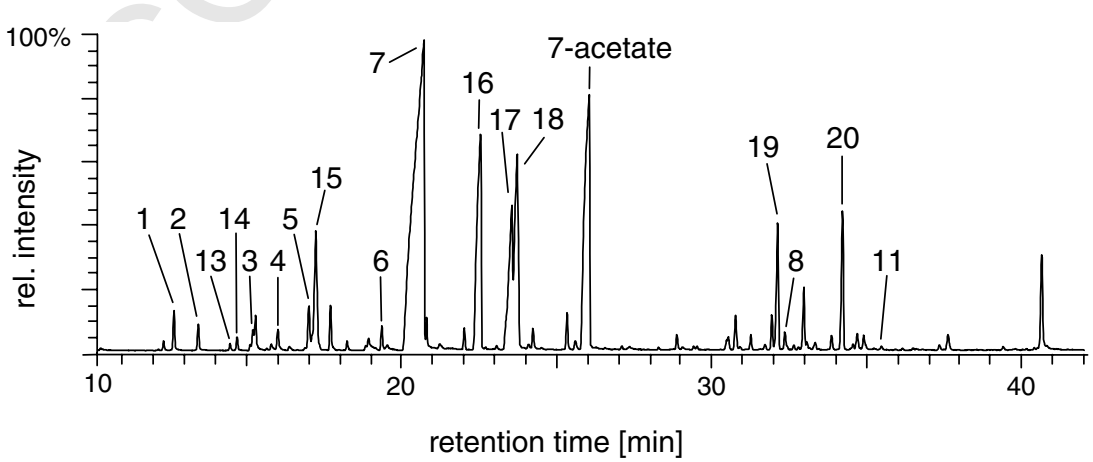

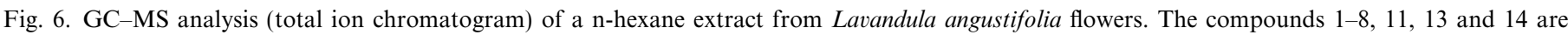

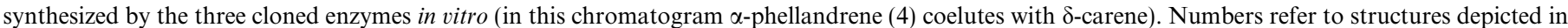

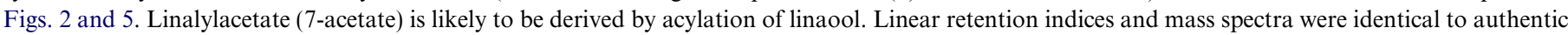

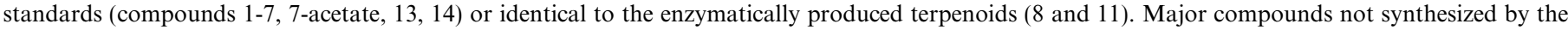

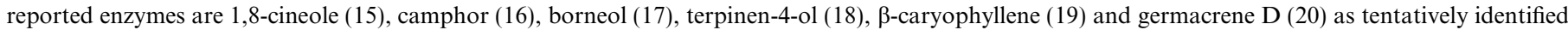
by comparison with the mass spectra database. All other components of the essential oil were not identified. 


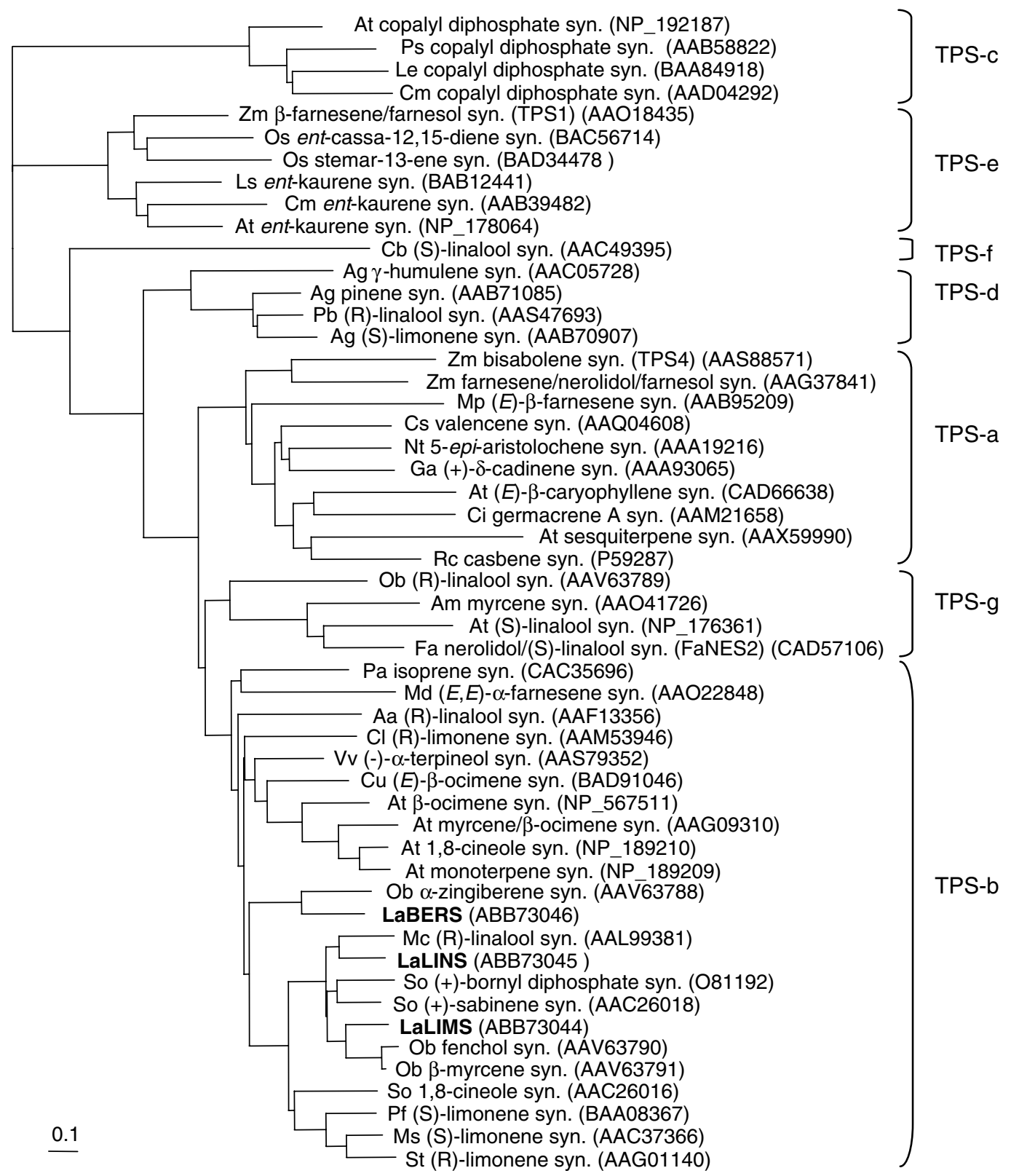

Fig. 7. A neighbour-joining phylogenetic tree of selected biochemically characterized terpene synthases from various species including LaLIMS, LaLINS and LaBERS. The tree was rooted to the copalyl diphosphate synthases (TPS-c), which were defined as out-group using the software Treeview [60]. The seven classes of TPS-a to TPS-g are clearly separated [24,51]. The terpene synthases cloned from Lavandula angustifolia are part of the class TPS-b that contains predominantly monoterpene synthases of angiosperms. The GenBank accession numbers of all sequences are given in parentheses. The following abbreviations are used for the plants: Aa, Artemisia annua; Ag, Abies grandis; Am, Antirrhinum majus; At, Arabidopsis thaliana; Cb, Clarkia breweri; Ci, Cichorium intybus; $\mathrm{Cl}$, Citrus limon; $\mathrm{Cm}$, Cucurbita maxima; Cs, Citrus sinensis; $\mathrm{Cu}$, Citrus unshiu; Fa, Fragari * ananassa; Ga, Gossypium arboreum; Le, Lycopersicum esculentum; Ls, Lactuca sativa; Mc, Mentha citrata; Md, Malus domestica; Mp, Mentha $\times$ piperata; Ms, Mentha spicata; Nt, Nicotiana tabacum; Ob, Ocimum basilicum; Os, Oryza sativa; Pa, Populus alba $\times$ Populus tremula; Pb, Picea abies; Pf, Perilla frutescens; Ps, Pisum sativum; Rc, Ricinus communis; So, Salvia officinalis; St, Schizunepeta tenuifolia; $\mathrm{Vv}$, Vitis vinifera; $\mathrm{Zm}$, Zea mays.

thases from C. breweri [23], A. thaliana [20] and Fragaria $\times$ ananassa [54] are more distantly related, but they all transform geranyl diphosphate to exclusively one product. Only the $(R)$-linalool synthase from the gymnosperm species Picea abies synthesizes small amounts $(<2 \%)$ of other monoterpenes [55]. Compared to terpene cyclization the reaction mechanism of linalool formation is simple. After initial ionization of geranyl diphosphate, the geranyl cation reacts directly with water resulting in $(R)$ - or $(S)$-linalool depending on the side of attack $[46,56]$. Active site modeling of the linalool synthase from $M$. citrata and two monoterpene cyclases has shown that an amino acid loop that prevents water access to the carbocationic intermediates is dislocated in the linalool synthase [46]. In the terpene cyclases this loop comprises three amino acids of the C-terminal region that are missing in the linalool synthase. The same deletion can be found in the sequence of LaLINS between aa547 and aa548 (Fig. 1). In contrast LaLIMS 
and LaBERS contain these three amino acids and are capable of cyclization reactions, thus confirming the importance of this sequence element. Like the enzyme from M. citrata LaLINS can be regarded as a 'defective' form of a terpene cyclase that is only capable of catalyzing the first ionization step [46]. It can be assumed that for the same reason linalool synthases developed in all TPS subclasses independently, representing 'defective' forms of very diverse parental enzymes.

LaBERS is like the $\alpha$-zingiberene synthase from $O$. basilicum more closely related to monoterpene synthases than to sesquiterpene synthases of the TPS-a group. It is likely that these enzymes were derived directly from monoterpene synthases by losing their signal peptide and broadening substrate acceptance to include farnesyl diphosphate [27]. This idea is supported by the fact that LaBERS accepts geranyl diphosphate with higher substrate affinity (lower $K_{\mathrm{m}}$ ). It is remarkable that the enzyme did not lose the ability to perform complex cyclization reactions when it changed the conformation of its active site to allow the transformation of farnesyl diphosphate. In fact the product specificity of LaBERS is comparatively high for a sesquiterpene synthase. In contrast the third sesquiterpene synthase of group TPS-b, the $(E, E)$ - $\alpha$-farnesene synthase from $M$. domestica [57] may also be a 'defective' form of a parental monoterpene synthase as it is only able to catalyze the elimination of diphosphate forming $(E, E)$ - $\alpha$-farnesene.

The sequences of the cloned enzymes LaLIMS, LaLINS and LaBERS described in this report lay the basis for the genetic modification of the flavor profile of this economically important essence. Transgenic lines of two other widely cultivated Lavandula species, Lavandula $\times$ intermedia and L. latifolia, have already been successfully bred, suggesting that additional transgenic lines are soon to come $[58,59]$. L. latifolia was modified by upregulating 1-deoxyD-xylulose-5-phosphate synthesis, a key intermediate of plastidial terpene biosynthesis, resulting in elevated levels of monoterpenes. Thus, our results help pave the way to the specific control of the composition of the essential oil from $L$. angustifolia.

\section{Acknowledgments}

We thank Peter Schieberle for providing deuteriumlabeled linalool and Heather Coiner for correcting the manuscript.

\section{References}

[1] V. McNaughton, Lavender the Grower's Guide, Timber Press, Portland, 2000.

[2] J. Segura, M.C. Calvo, in: Y.P.S.Hrsg. Bajaj (Ed.), Biotechnology in agriculture and forestry, Medicinal and Aromatic Plants III, vol. 15, Springer, Berlin, 1991, pp. 283-310.

[3] D. Bown, The Royal Horticultural Society. Die neue KräuterEnzyklopädie. Anbau und Verwendung. Dorling Kindersley, Starnberg (2005).

[4] N.S. Kim, D.S. Lee, J. Chromatogr. A. 982 (2002) 31-47.
[5] E. Basch, I. Foppa, R. Liebowitz, J. Nelson, M. Smith, D. Sollars, C. Ulbricht, J. Herbal Pharmacother. 4 (2004) 63-78.

[6] M.L. Wise, R. Croteau, in: Cane D. Hrsg (Ed.), Comprehensive natural products chemistry, Isoprenoids Including Carotenoids and Steroids, vol. 15, Elsevier, Oxford, 1999, pp. 97-153.

[7] K.P. Svoboda, T.G. Svoboda, A.D. Syred, HerbalGram 53 (2001) 34-43.

[8] B.M. Lawrence, Perfumer Flavorist 18 (1) (1993) 53-61.

[9] B.M. Lawrence, Perfumer Flavorist 19 (3) (1994) 33-40.

[10] R. Shellie, P. Marriott, C. Cornwell, HRC J. High Resolution Chromatogr. 23 (2000) 554-560.

[11] R. Shellie, L. Mondello, P. Marriott, G. Dugo, J. Chromatogr. A. 970 (2002) 225-234.

[12] A.R. Fakhari, P. Salehi, R. Heydari, S.N. Ebrahimi, P.R. Haddad, J. Chromatogr. A 1098 (2005) 14-18.

[13] J. Jung, S. Sewenig, U. Hener, A. Mosandl, Eur. Food Res. Technol. 220 (2005) 232-237.

[14] P. Kreis, A. Mosandl, Flavour Fragrance J. 7 (1992) 187-193.

[15] G. Flores, G.P. Blanch, M.L. Ruiz del Castillo, M. Herraiz, J. Sep. Sci. 28 (2005) 2333-2338.

[16] P.J. Facchini, J. Chappell, Proc. Natl. Acad. Sci. USA 89 (1992) 11088-11092.

[17] S.M. Colby, W.R. Alonso, E.J. Katahira, D.J. McGarvey, R Croteau, J. Biol. Chem. 268 (1993) 23016-23024.

[18] J. Bohlmann, D. Martin, N.J. Oldham, J. Gershenzon, Arch Biochem. Biophys. 375 (2000) 261-269.

[19] F. Chen, D.K. Ro, J. Petri, J. Gershenzon, J. Bohlmann, E. Pichersky, D. Tholl, Plant Physiol. 135 (2004) 1956-1966.

[20] F. Chen, D. Tholl, J.C. D'Auria, A. Farooq, E. Pichersky, J. Gershenzon, Plant Cell 15 (2003) 481-494.

[21] J. Fäldt, G.I. Arimura, J. Gershenzon, J. Takabayashi, J. Bohlmann, Planta. J. 216 (2003) 745-751.

[22] D. Tholl, F. Chen, J. Petri, J. Gershenzon, E. Pichersky, Plant J. 42 (2005) 757-771.

[23] N. Dudareva, L. Cseke, V.M. Blanc, E. Pichersky, Plant Cell 8 (1996) $1137-1148$.

[24] J. Bohlmann, C.L. Steele, R. Croteau, J. Biol. Chem. 272 (1997) 21784-21792.

[25] J. Bohlmann, G. Meyer-Gauen, R. Croteau, Proc. Natl. Acad. Sci. USA 95 (1998) 4126-4133.

[26] J. Bohlmann, M. Phillips, V. Ramachandiran, S. Katoh, R. Croteau, Arch. Biochem. Biophys. 368 (1999) 232-243.

[27] Y. Iijima, R. Davidovich-Rikanati, E. Fridman, D.R. Gang, E. Bar, E. Lewinsohn, E. Pichersky, Plant Physiol. 136 (2004) 3724-3736.

[28] M.L. Wise, T.J. Savage, E. Katahira, R. Croteau, J. Biol. Chem. 273 (1998) 14891-14899.

[29] J. Lücker, M.K. El Tamer, W. Schwab, F.W.A. Verstappen, L.H.W. Van der Plas, H.J. Bouwmeester, H.A. Verhoeven, Eur. J. Biochem. 269 (2002) 3160-3171.

[30] C. Schnee, T.G. Köllner, J. Gershenzon, J. Degenhardt, Plant Physiol. 130 (2002) 2049-2060.

[31] T.G. Köllner, C. Schnee, J. Gershenzon, J. Degenhardt, Plant Cell 16 (2004) 1115-1131.

[32] C.L. Steele, E. Lewinsohn, R. Croteau, Proc. Natl. Acad. Sci. USA 92 (1995) 4164-4168.

[33] S.F. Altschul, T.L. Madden, A.A. Schäffer, J. Zhang, Z. Zhang, W. Miller, D.J. Lipman, Nucleic Acids Res. 25 (1997) 3389-3402.

[34] D.C. Williams, D.J. McGarvey, E.J. Katahira, R. Croteau, Biochemistry 37 (1998) 12213-12220.

[35] M.M. Bradford, Anal. Biochem. 72 (1976) 248-254.

[36] D.A. Whittington, M.L. Wise, M. Urbansky, R.M. Coates, R.B Croteau, D.W. Christianson, Proc. Natl. Acad. Sci. USA 99 (2002) $15375-15380$.

[37] D.W. Christianson, Chem. Rev. 106 (2006) 3412-3442.

[38] P. McGeady, R. Croteau, Arch. Biochem. Biophys. 317 (1995) 149 155.

[39] K. Keegstra, L.J. Olsen, S.M. Theg, Ann. Rev. Plant Physiol. Plant Mol. Biol., 40 (1989) 471-501. 
[40] G. von Heijne, J. Stepphuhn, R.G. Herrmann, Eur. J. Biochem., 180 (1989) 535-545.

[41] G. Turner, J. Gershenzon, E.E. Nielson, J.E. Froehlich, R. Croteau, Plant Physiol. 120 (1999) 879-886.

[42] J. Bohlmann, J. Crock, R. Jetter, R. Croteau, Proc. Natl. Acad. Sci. USA 95 (1998) 6756-6761.

[43] S.C. Trapp, R.B. Croteau, Genetics 158 (2001) 811-832.

[44] H. Gambliel, R. Croteau, J. Biol. Chem. 259 (1984) 740-748.

[45] W. Alonso, R. Croteau, Arch. Biochem. Biophys. 286 (1991) 511-517.

[46] A.L. Crowell, D.C. Williams, E.M. Davis, M.R. Wildung, R. Croteau, Arch. Biochem. Biophys. 405 (2002) 112-121.

[47] A.O. Eshilokun, A.A. Kasali, A.O. Giwa-Ajeniya, Flavour Fragrance J. 20 (2005) 528-530.

[48] A. Verzera, A. Trozzi, A. Cotroneo, D. Lorenzo, E. Dellacassa, J. Agric. Food Chem., 48 (2000) 2903-2909.

[49] J.D. da Silva, A.I.R. Luz, M.H.L. da Silva, E.H.A. Andrade, M.G.B. Zoghbi, J.G. S Maia, Flavour Fragrance J. 18 (2003) 240-243.

[50] C. Schnee, T.G. Köllner, M. Held, T.C.J. Turlings, J. Gershenzon, J. Degenhardt, Proc. Natl. Acad. Sci. USA 103 (2006) 1129-1134.
[51] N. Dudareva, D. Martin, C.M. Kish, N. Kolosova, N. Gorenstein, J. Fäldt, B. Miller, J. Bohlmann, Plant Cell. 15 (2003) 1227-1241.

[52] D. Tholl, Curr. Opin. Plant Biol. 9 (2006) 297-304.

[53] J.W. Jia, J. Crock, S. Lu, R. Croteau, X.Y. Chen, Arch. Biochem. Biophys. 372 (1999) 143-149.

[54] A. Aharoni, A.P. Giri, F.W.A. Verstappen, C.M. Bertea, R. Sevenier, Z. Sun, M.A. Jongsma, W. Schwab, H.J. Bouwmeester, Plant Cell 16 (2004) 3110-3131.

[55] D.M. Martin, J. Fäldt, J. Bohlmann, Plant Physiol. 135 (2004) 19081927.

[56] E. Pichersky, E. Lewinsohn, R. Croteau, Arch. Biochem. Biophys. 316 (1995) 803-807.

[57] S.W. Pechous, B.D. Whitaker, Planta 219 (2004) 84-94.

[58] S. Dronne, S. Moja, F. Jullien, F. Berger, J.-C. Caissard, Transgenic Res. 8 (1999) 335-347.

[59] J. Munoz-Bertomeu, I. Arrillaga, R. Ros, J. Segura, Plant Physiol., 142 (2006) 890-900.

[60] R.D.M. Page, Comput. Appl. Biosci. 12 (1996) 357-358. 